\title{
Postoperative cognitive dysfunction after robot-assisted radical cystectomy (RARC) with cerebral oxygen monitoring an observational prospective cohort pilot study
}

\author{
Yue $\mathrm{Li}^{\dagger}$, Dan Huang ${ }^{\dagger}$, Diansan Su, Jie Chen and Liqun Yang ${ }^{*}$ (iD
}

\begin{abstract}
Background: The incidence and risk factors of postoperative cognitive dysfunction (POCD) during robot-assisted radical cystectomy (RARC) in extreme Trendelenburg positioning and pneumoperitoneum are still controversial. The aim of this prospective observational study was to find the incidence rate as well as possible risk factors of POCD in RARC with cerebral oxygen monitoring.

Methods: Patients who underwent RARC and open abdominal surgery in horizontal positioning were included. Preoperative and postoperative arterial blood gas (ABG), S-100ß, C-reactive protein (CRP), and cognitive dysfunction scales were tested. Also, we used $Z$ score to analyze and comprehensively evaluate POCD. Measurements of heart rate $(\mathrm{HR})$, mean arterial pressure (MAP), central venous pressure (CVP), end-tidal $\mathrm{CO}_{2}$ (etCO $\mathrm{CO}_{2}$ ), and cerebral oxygen were immediately obtained after different time points during the surgery.

Results: Here, 24 and 23 patients were included in the RARC group and in the control group, respectively. The incidence of POCD didn't have significant difference in RARC group (45.8\%), in contrast to the control group (26.1\%). The laboratory tests of $s 100 \beta$ and CRP between two groups didn't contain significant difference as well. As duration of Trendelenburg and pneumoperitoneum prolonged, the cerebral oxygen saturation in the RARC group increased, which didn't cause excessive perfusion nevertheless ( $\left.\mathrm{rSO}_{2}<75 \%\right)$. We compared laboratory tests, age, education status, blood loss, and fluid input between POCD and non-POCD patients. A significant difference was found in the serum concentrations of CRP (72.59 \pm 42.09 vs. $48.50 \pm 26.53, P=0.025)$ and age $(69.20 \pm 7.033$ vs. $65.34 \pm 5.228, P=0.041$ ).
\end{abstract}

Conclusion: RARC in extreme Trendelenburg positioning and pneumoperitoneum did not significantly increase the incidence of POCD and didn't cause excessive perfusion. The inflammation marker CRP and age might be independent risk factors of POCD.

Trial registration: Clinicaltrials.gov with registration number NCT03372135. Registered 1 November 2017 (retrospectively registered).

Keywords: Postoperative cognitive dysfunction, Robot-assisted radical cystectomy, Cerebral oxygen saturation

\footnotetext{
* Correspondence: layang72721@126.com

${ }^{\dagger}$ Yue Li and Dan Huang contributed equally to this work as first authors.

Department of Anesthesiology, Renji Hospital, School of Medicine, Shanghai

Jiaotong University, 160 Pujian Road, Shanghai 200127, China
}

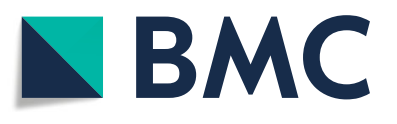

(c) The Author(s). 2019 Open Access This article is distributed under the terms of the Creative Commons Attribution 4.0 International License (http://creativecommons.org/licenses/by/4.0/), which permits unrestricted use, distribution, and reproduction in any medium, provided you give appropriate credit to the original author(s) and the source, provide a link to the Creative Commons license, and indicate if changes were made. The Creative Commons Public Domain Dedication waiver (http://creativecommons.org/publicdomain/zero/1.0/) applies to the data made available in this article, unless otherwise stated. 


\section{Background}

Bladder cancer is one of the most common malignancies throughout the world [1] due to its high morbidity and mortality $[2,3]$. There is an increasing intention in the use of robot-assisted radical cystectomy (RARC) because of improved short-term outcome in addition to functional results $[4,5]$. One of its potential disadvantages is the necessity of extreme Trendelenburg position and $\mathrm{CO}_{2}$ pneumoperitoneum, which lead to complex pathophysiological changes [6, 7].

Pneumoperitoneum can cause an increase in intracranial pressure (ICP), which is partly related to an decreased drainage of the lumbar venous plexus [8, 9]. It can be explained by the modified Monroe-Kelly doctrine [9] that a change in one or more compartments of the intracranial space leads to a compensatory change in the remaining components. If changes would be occurred too fast to compensate, the ICP rises. Accordingly, pneumoperitoneum may bring about an increase in the ICP since the lumbar venous plexus reflux decreases.

Increased intra-abdominal pressure (IAP) can exert mechanical compression on vessels. A small decrease in the vessel diameters may lead to a remarkable decrease of the blood flow. Increased IAP may also stimulate the release of vasopressin, which can induce vasoconstriction. In addition, the brain is extremely sensitive to the change of $\mathrm{pCO}_{2}$. Prolonged time of pneumoperitoneum caused by carbon dioxide retention or even hypercapnia, may also lead to increase of intracranial pressure secondary to cerebral vascular expansion. The ICP elevation along with pneumoperitoneum further increases in the extreme Trendelenburg positioning, which may rise the risk of brain edema, blood-brain barrier damage, as well as potential brain injury caused by the decrease of cerebral perfusion and insufficient supply of oxygen.

Therefore, surgery in a steep Trendelenburg position and pneumoperitoneum might also affect cerebral integrity due to increased ICP and potential cerebral edema formation $[10,11]$. These effects may possibly result in abnormal brain perfusion as well as anomalous cerebral oxygen supply $[12,13]$. Additionally, the prolonged duration of operation (at least $3 \mathrm{~h}$ for extreme Trendelenburg positioning and pneumoperitoneum) may exacerbate the effects on elderly patients with relatively weak vascular walls $[6,10]$, which may result in POCD. Near-infrared spectroscopy (NIRS) can assist us to observe the position of cerebral perfusion. It is a relatively new technology for monitoring non-invasive regional cerebral oxygen saturation $\left(\mathrm{rSO}_{2}\right)$. NIRS can penetrate to the brain with a depth of $1 \sim 2 \mathrm{~cm}$ [14] in a certain range $(650-1100 \mathrm{~nm})$. In the brain, the arteries and veins are staggered (veins $75 \%$, arteries $20 \%$, and capillaries account for $5 \%$ ), indicating that the value of local cerebral oxygen saturation mainly represents the oxygen content in the venous blood, reflecting the cerebral oxygen transportation and metabolism. Recent studies have shown that decreased cerebral oxygen value (more than $25 \%$ of the base value) can increase the incidence rate of multiple organ dysfunction syndrome (MODS) and prolong ICU as well as average length of stay in hospital. The present study investigated the $\mathrm{rSO}_{2}$ value of the brain to observe the cerebral perfusion and oxygen metabolism during specific procedures.

POCD is a short-run decline in cognitive function after surgery, which may last from a few days to a few weeks. It is a common and influential outcome of surgical procedures in the aged. The mechanisms and pathophysiology for POCD have been poorly perceived. One possible biological mechanism for an impact on brain protein deposition may exist. However, the current knowledge is very limited. POCD is supposed to be associated with several factors such as age, trauma, inflammation, surgical stress, position, fluid, mean blood pressure, artificial pneumoperitoneum, and so on $[15,16]$. With the advent of global aging and the development of robotic surgery, more elderly people will receive such surgical treatments, and the medical and social problems generated by POCD will become markedly serious.

Thus, our hypothesis was that the incidence of POCD in patients who underwent RARC would be higher than those who underwent open abdominal surgery in horizontal position. Accordingly, our primary aim was to observe the combined effect of Trendelenburg position and $\mathrm{CO}_{2}$ pneumoperitoneum on POCD during RARC with monitoring the cerebral oxygen. Our secondary aim was to determine probable risk factors of POCD.

\section{Methods \\ Study design}

This was an observational prospective cohort pilot study, which was approved by our Institutional Review Board and was registered by the Clinical Research Information Service (Clinical Trial.gov ID: NCT03372135).

\section{Subjects}

The study was conducted between December 2017 and May 2018. Patients (with the age of more than 55 years old, ASA I-III) who underwent RARC and open abdominal surgery in horizontal position were included. All recipients were free of intracranial surgery and intracranial pathology (e.g., cerebral infarction). We also excluded patients who suffered from alcoholism or took psychotropic medication. Illiteracy, visual and hearing impairment and those who affected by low preoperative minimental state examination (MMSE) scores (less than 24) were eliminated as well. 


\section{Preoperative and postoperative tests}

Regarding preoperative cognitive dysfunction scales, Creactive protein (CRP) and S-100 $\beta$ were tested. Laboratory variables of S-100 $\beta$ (brain injury biomarker) and CRP (an acute-phase protein in response to inflammation) were measured $48 \mathrm{~h}$ after surgery as well. Cognitive dysfunction scales were used to evaluate patients in the period of 1 week and 3 months [17] after surgery to compare with preoperative results. The test battery [18] included MMSE, a test of examination of functions including registration, attention and calculation, recall, language, ability to follow simple commands, and orientation; Brief Visuospatial Memory Test-Revised (BVMT-R), an assessment of non-verbal learning and memory; Symbol Digit Modalities Test, a test of psychomotor speed and attentional control; Trail Making Test (TMT), to assess visual scanning, psychomotor speed, attention, and executive function; Digit Span Test (DST), measuring attention and short-term verbal memory; and Stroop Color and Word Test (SCWT), a test for word-naming and resistance to interference. These tests were administered by experienced research personnel, who trained and supervised by a senior neuropsychologist.

\section{Position and insufflation during RARC}

$\mathrm{CO}_{2}$ pneumoperitoneum with a stable abdominal pressure of $1.2 \mathrm{kPa}$ and flow of $1.5 \mathrm{kPa}$, accompanied with 40 to $45^{\circ}$ Trendelenburg positioning were performed in all patients in RARC group after anesthesia induction. When bladder isolation, ureters blocking, and lymph node dissection finished, patients were returned to the horizontal position and deflation.

\section{General anesthesia and monitoring}

After a recipient was placed supine in the operating room, routine monitoring was performed using electrocardiography, pulse oximetry, non-invasive blood pressure, and end-tidal $\mathrm{CO}_{2}\left(\right.$ etCO $\left.\mathrm{CO}_{2}\right)$. In accordance with our protocol, anesthesia was induced with propofol and sufentanil, with tracheal intubation facilitated with Rocuronium bromide. Anesthesia was maintained with sevoflurane in a $60 \%$ oxygen-air mixture accompanied by continuous infusions of remifentanil and cisatracurium. Then, the direct arterial pressure was monitored by femoral arterial catheterization. To monitor central venous pressure, a central venous catheter inserted into the internal jugular vein was connected to a sensor.

\section{Measurements of cerebral rSO2 and intraoperative variables}

NIRS can be used to detect changes in oxygenated and deoxygenated hemoglobin associated with brain tissue hypoxia and estimate changes in cerebral blood volume and flow. For cerebral oximetry, sensors were placed on the patient's forehead bilaterally. Cerebral $\mathrm{rSO}_{2}$ values were obtained from an INVOS 5100C Cerebral/Somatic Oximeter System, which generates 2 wavelengths of infrared light (730 and $805 \mathrm{~nm}$ ) and penetrates into the skull and cerebral tissues. The cerebral oximetry sensor is consisted of a light-emitting diode and 2 detectors located at distances of 30 and $40 \mathrm{~mm}$ from the lightemitting diode to avoid light attenuation or extracranial contamination. Cerebral $\mathrm{rSO}_{2}$ values were automatically recorded every 5-6 s from the digital output port of the monitor to the personal computer.

Measurements of heart rate (HR), mean arterial pressure (MAP), central venous pressure (CVP), etCO $\mathrm{C}_{2}$ and cerebral oxygen were simultaneously performed after entering the operating room (T0; baseline), anesthesia induction (T1), Trendelenburg positioning (T2), $1 \mathrm{~h}, 2 \mathrm{~h}$, and $3 \mathrm{~h}$ after Trendelenburg positioning (T3, T4, T5 respectively), and after desufflation in a horizontal position (T6). We obtained arterial blood gas and vein blood gas for measurements of hemoglobin $(\mathrm{Hb})$, serum glucose, sodium, potassium, base excess, lactic acid, $\mathrm{PaCO}_{2}$, $\mathrm{PaO}_{2}, \mathrm{PvCO}_{2}$, and $\mathrm{PvO}_{2}$ before the operation, and 10 min after desufflation.

\section{Neuropsychological assessment}

We used $\mathrm{Z}$ score to analyze and comprehensively evaluate POCD [19]. Six cognitive scores (MMSE, BVMT-R, Symbol Digit Modalities Test, TMT, DST, and SCWT) [20] were combined into a composite cognitive score by averaging the $\mathrm{Z}$ scores of each test from the patients' preoperative assessments. Thus, by definition, the mean preoperative score is 0 and the standard deviation is 1 . When there were significant findings $(\geq 1.96)$ in postoperative neurocognitive tests or the total $\mathrm{Z}$ score $\geq 1.96$, then the patients were defined as POCD [15]. In this calculation, timed test scores were inverted to be consistent with non-timed tests, such that higher values represent superior performance for all tests.

\section{Statistical analysis}

Data are presented as mean \pm standard deviation (SD). With Comparing the incidence rate of POCD, the concentration of CRP and s100 $\beta$ between RARC group and control group was compared using the one-tailed Fisher's exact test and independent sample t-test. Nonparametric test (Kruskal-Wallis test) was used for the cerebral oxygen saturation value and vital signs of RARC group during different time points. $P$-value of less than 0.05 was statistically considered significant. Statistical analysis was performed using the GraphPad Prism 5.01 software (GraphPad Inc., CA, USA). 


\section{Result}

\section{Demographic factors and intraoperative variables}

A total of 50 patients were initially enrolled in this study, but 3 patients ( 1 in RARC group and 2 in the control group) were dropped out because of failure in data collection. Other 47 patients, including 24 cases in RARC group and 23 patients in the control group were enrolled as shown in Table 1. All operations and neuropsychological tests carried out well. Patients' characteristics, including age, sex, body mass index (BMI), education status, Basal MMSE, Basal $\mathrm{rSO}_{2}$, and American Standards Association (ASA) classes II-III, were not different between the two groups $(P>0.05$, Table 1$)$. General data of surgery, including duration of Trendelenburg and operation, blood loss, and input fluid volume did not contain significant difference between those two groups $(P>0.05$, Table 1$)$. There were no significant differences in $\mathrm{HR}, \mathrm{CVP}, \mathrm{rSO}_{2}$, and $\mathrm{SpO}_{2}$ between two groups during surgery, while MAP was different at the point of Trendelenburg position and pneumoperitoneum (T1 vs. T2) (71.92 \pm 7.751 vs. $93.25 \pm 6.771, P<0.05$, Table 2$)$. The etCO $\mathrm{C}_{2}$ increased as the duration of Trendelenburg position and pneumoperitoneum prolonged (T2 vs. T5) (from $33.92 \pm 1.881$ to $44.00 \pm 5.461, P<0.05$ ).

We obtained arterial blood gas and vein blood gas before the operation and $10 \mathrm{~min}$ after desufflation. Our results showed that there was no significant difference between two groups preoperatively (Table 3). However, the differences in the lactic acid $(1.421 \pm 0.356$ vs. $1.131 \pm 0.296, P=0.030), \mathrm{PaCO}_{2}$ and $\mathrm{PvCO}_{2}(43.08 \pm$ 4.057 vs. $39.37 \pm 4.417, \quad P=0.032 ; 50.21 \pm 5.047$ vs. $46.12 \pm 3.779, P=0.028$ ) were significantly increased 10 min after desufflation in RARC group in contrast to the control group. The other variables didn't have any significant difference (Table 4).

Table 1 Patients' characteristics (mean \pm SD)

\begin{tabular}{llll}
\hline Characteristic & RARC group $(n=24)$ & Control group $(n=23)$ & $P$-value \\
\hline Sex, M/F & $20 / 4$ & $16 / 7$ & 0.277 \\
Age, y & $67.75 \pm 7.385$ & $65.35 \pm 4.097$ & 0.177 \\
$\mathrm{BMI}, \mathrm{kg} / \mathrm{m}^{2}$ & $23.26 \pm 3.298$ & $22.23 \pm 2.430$ & 0.232 \\
$\mathrm{ASA}$ & $2.000 \pm 0.135$ & $1.870 \pm 0.114$ & 0.466 \\
Education status & $2.667 \pm 1.050$ & $2.174 \pm 0.937$ & 0.097 \\
Basal MMSE & $28.75 \pm 0.235$ & $28.61 \pm 0.279$ & 0.700 \\
Basal rSO & $63.93 \pm 5.175$ & $64.63 \pm 3.363$ & 0.697 \\
Trendelenburg & $251.8 \pm 69.72$ & $227.4 \pm 47.92$ & 0.171 \\
time/ Operation & & & \\
time, min & & & 0.326 \\
Blood loss, $\mathrm{mL}$ & $166.0 \pm 132.7$ & $130.9 \pm 110.1$ & 0.322 \\
\hline Input fluid, $\mathrm{mL}$ & $2204 \pm 585.8$ & $2043 \pm 519.0$ & \\
\hline
\end{tabular}

Education status: 1 = elementary school; 2 = middle school; $3=$ high school; $4=$ college/university. $P$-value is compared between the RARC group and control group

\section{Cerebral oxygen saturation}

The average basic $\mathrm{rSO}_{2}$ monitored by the INVOS 5100C cerebral oximeter system was $63.06 \pm 3.222$ in RARC group and $64.63 \pm 3.363$ in the control group $(P=0.697)$. In comparison with the control group, $\mathrm{rSO}_{2}$ value increased as duration of Trendelenburg position and pneumoperitoneum was prolonged in the RARC group (from $65.80 \pm 3.768$ to $68.58 \pm 3.510$ ). However, all the $\mathrm{rSO}_{2}$ values remained well below the threshold value of $75 \%$, demonstrating that cerebral excessive perfusion is very unlikely. After repositioning, $\mathrm{rSO}_{2}$ gradually decreased (Table 2, Figs. 1 and 2).

\section{Neuropsychological tests}

Herein, 11 patients were diagnosed as whom having POCD after $7 \mathrm{~d}$ in the RARC group, and the incidence rate of POCD was $45.83 \%$. In the control group, 6 patients had POCD and the incidence rate of POCD was 26.09\%. No significant difference in the incidence rate of POCD between the two groups (OR [95\%CI], 0.42 [0.12-1.43]; $P=0.135)$ was achieved. However, the TMT's score 1 week after operation in RARC group was significantly higher than the control group $(153.5 \pm 64.30$ vs. $116.1 \pm 60.39, P=0.045$, Table 4$)$. We listed several probable risk factors of POCD, and we found that age $(69.20 \pm 7.033$ vs. $65.34 \pm 5.228, P=0.041)$ and postoperative CRP $(72.59 \pm 42.09$ vs. $48.50 \pm 26.53, P=0.025)$ had significant difference between patients with and without POCD postoperatively (Table 6).

\section{Blood assay}

s100 $\beta$ significantly increased at stage of $48 \mathrm{~h}$ after operation compared with the preoperative stage in both groups $(295.4 \pm 172.9$ vs. $110.2 \pm 45.79, P<0.001 ; 258.9 \pm 179.1$ vs. $99.80 \pm 57.10, P<0.001)$. Besides, CRP increased at stage of $48 \mathrm{~h}$ after operation in both groups $(54.09 \pm 38.80$ vs. $2.083 \pm 3.221, P<0.001 ; 61.06 \pm 29.33$ vs. $2.448 \pm 2.987$, $P<0.001)$. Before surgery and $48 \mathrm{~h}$ after surgery, s100 $\beta$ and CRP had no significant difference between RARC group and the control group $(P>0.05$, Table 5$)$. There were no significant differences in the serum concentrations of $s 100 \beta$ between patients with and without POCD postoperatively $(P>0.05$, Table 6$)$, while a significant difference was found in the serum concentrations of CRP $(72.59 \pm 42.09$ vs. $48.50 \pm 26.53, P=0.025)$.

\section{Discussion}

POCD

POCD was initially recognized as a common neurological complication secondary to anesthesia and surgery in 1955. The pathogenesis of POCD has not been properly clarified, and there are not sufficient validated risk models for POCD. Advanced age has been considered as an independent risk factor for developing POCD in 
Table $2 \mathrm{rSO}_{2} / \mathrm{SpO}_{2} / \mathrm{etCO}_{2} / \mathrm{MAP} / \mathrm{HR} / \mathrm{CVP}$ of the sample in RARC group (mean $\pm \mathrm{SD}$ )

\begin{tabular}{lllllll}
\hline & $\mathrm{rSO}_{2}(\%)$ & $\mathrm{SpO}_{2}(\%)$ & $\mathrm{P}_{\mathrm{et}} \mathrm{CO}_{2}(\mathrm{mmHg})$ & $\mathrm{MAP}(\mathrm{mmHg})$ & $\mathrm{HR}(\mathrm{bpm})$ & $\mathrm{CVP}(\mathrm{mmH} 2 \mathrm{O})$ \\
\hline $\mathrm{T} 0$ & $63.06 \pm 3.222$ & $99.22 \pm 1.095$ & & $99.08 \pm 13.03$ & $70.42 \pm 5.915$ & $7.500 \pm 0.798$ \\
$\mathrm{~T} 1$ & $63.34 \pm 4.008$ & $99.39 \pm 1.196$ & $30.50 \pm 1.087$ & $71.92 \pm 7.751$ & $63.83 \pm 11.53$ & $8.167 \pm 1.642$ \\
$\mathrm{~T} 2$ & $65.80 \pm 3.768$ & $99.91 \pm 0.288$ & $33.92 \pm 1.881$ & $93.25 \pm 6.771^{* a}$ & $59.67 \pm 10.30$ & $7.833 \pm 1.801$ \\
$\mathrm{~T} 3$ & $67.09 \pm 4.345$ & $99.91 \pm 0.288$ & $39.83 \pm 3.786$ & $78.67 \pm 7.499$ & $63.42 \pm 4.358$ & $9.333 \pm 2.188$ \\
$\mathrm{~T} 4$ & $67.99 \pm 4.488$ & $99.83 \pm 0.388$ & $41.67 \pm 5.033$ & $76.25 \pm 5.818$ & $67.83 \pm 8.089$ & $9.000 \pm 1.954$ \\
$\mathrm{~T} 5$ & $68.58 \pm 3.510$ & $99.78 \pm 0.518$ & $44.00 \pm 5.461^{* b}$ & $78.56 \pm 6.659$ & $68.83 \pm 7.493$ & $9.333 \pm 2.103$ \\
$\mathrm{~T} 6$ & $67.61 \pm 3.351$ & $99.87 \pm 0.458$ & $41.42 \pm 5.869$ & $77.88 \pm 7.159$ & $72.50 \pm 7.972$ & $10.08 \pm 1.621$ \\
$\mathrm{~T} 7$ & $67.05 \pm 2.937$ & $100 \pm 0.0$ & $36.00 \pm 2.954$ & $83.88 \pm 8.794$ & $66.75 \pm 6.538$ & $10.33 \pm 1.557$ \\
\hline
\end{tabular}

$\mathrm{T} 0=$ Baseline; $\mathrm{T} 1$ = anesthesia induction; $\mathrm{T} 2=$ Trendelenburg position and pneumoperitoneum; $\mathrm{T} 3=1 \mathrm{~h}$ after Trendelenburg position and pneumoperitoneum; $\mathrm{T} 4=2 \mathrm{~h}$ after Trendelenburg position and pneumoperitoneum; $\mathrm{T} 5=3 \mathrm{~h}$ after Trendelenburg position and pneumoperitoneum; T6 $=$ repositioning; $\mathrm{T} 7=\mathrm{end}$ of procedure; *a = significance of difference between T1 and T2 $(P<0.05) ;{ }^{*} \mathrm{~b}=$ significance of difference between $\mathrm{T} 2$ and $\mathrm{T} 5(P<0.05)$

$\mathrm{rSO}_{2}=$ regional cerebral oxygen saturation measured with INVOS; $\mathrm{SpO}_{2}=$ peripheral oxygen saturation; $\mathrm{P}_{\mathrm{et}} \mathrm{CO}_{2}=$ end-expiratory $\mathrm{CO}_{2}$ partial pressure; bpm = beats per $\min$

several large cohort studies. The other risk factors mainly involve larger and more invasive operations, depth and duration of anesthesia, inflammation, change of ICP and CPP during surgery, etc. This is in agreement with the results of our study that age and postoperative CRP are independent risk factors of POCD.

Approximately $12 \%$ of patients who underwent anaesthesia and non-cardiac surgery will develop symptoms of cognitive dysfunction after their procedures [18]. In our study, the incidence rate of POCD in RARC reached up to $45.8 \%$, which was higher than the laparotomy group. However, no significance was achieved even with a relatively substantial odds ratio. The wide range of the confidential interval may be explained by the limited case numbers included in our study. Considering the present findings, the association between POCD and RARC in this pilot study is not explicit. Nevertheless, to a certain extent, our results make sense to the necessity of further large sample of clinical studies.
In addition, the scores of MMSE and DST 3 months after surgery were both improved in RARC group and control group, which demonstrated that the symptoms of cognitive dysfunction postoperatively might occur in a relatively short period of time, and long-term postoperative cognitive dysfunction was not observed in the present study.

\section{NIRS}

NIRS is used to assess regional cerebral oxygen saturation, presenting an indication for the balance between cerebral oxygen supply and consumption. Kalmar et al.'s study [11] reported that the $\mathrm{rSO}_{2}$ significantly increased when NIRS assessments were made with the subjects placed from the supine to the $20^{\circ}$ Trendelenburg position. Similarly, in the present study, $40^{\circ} \sim 45^{\circ}$ Trendelenburg position and $\mathrm{CO}_{2}$ pneumoperitoneum were associated with increase of $\mathrm{rSO}_{2}$ values in the brain. Throughout the duration of the procedure, $\mathrm{rSO}_{2}$ stayed well above the threshold value of $55 \%$ in each patient. At the beginning of Trendelenburg

Table 3 Preoperative and Postoperative arterial/vein blood gas

\begin{tabular}{|c|c|c|c|c|c|c|}
\hline & \multicolumn{3}{|l|}{ Preoperative } & \multicolumn{3}{|l|}{ Postoperative } \\
\hline & RARC group $(n=24)$ & Control group $(n=23)$ & P-value & RARC group $(n=24)$ & Control group $(n=23)$ & $P$-value \\
\hline $\mathrm{pH}$ & $7.430 \pm 0.037$ & $7.416 \pm 0.046$ & 0.405 & $7.351 \pm 0.051$ & $7.326 \pm 0.107$ & 0.442 \\
\hline $\mathrm{Hb}$ & $11.02 \pm 1.879$ & $11.26 \pm 2.276$ & 0.767 & $10.72 \pm 1.205$ & $11.13 \pm 1.933$ & 0.512 \\
\hline Glu & $6.050 \pm 0.836$ & $7.469 \pm 2.661$ & 0.069 & $7.829 \pm 1.312$ & $9.462 \pm 2.460$ & 0.050 \\
\hline Lac & $1.143 \pm 0.388$ & $0.977 \pm 0.277$ & 0.216 & $1.421 \pm 0.356$ & $1.131 \pm 0.296$ & $0.030^{*}$ \\
\hline $\mathrm{Na}^{+}$ & $139.5 \pm 2.210$ & $137.8 \pm 3.313$ & 0.137 & $142.7 \pm 3.474$ & $140.5 \pm 2.961$ & 0.093 \\
\hline $\mathrm{K}^{+}$ & $3.200 \pm 0.353$ & $3.469 \pm 0.382$ & 0.068 & $3.943 \pm 0.462$ & $3.938 \pm 0.741$ & 0.985 \\
\hline $\mathrm{BE}$ & $0.571 \pm 1.823$ & $-0.554 \pm 1.76$ & 0.116 & $-2.021 \pm 2.010$ & $-3.415 \pm 1.918$ & 0.078 \\
\hline $\mathrm{PaO}_{2}$ & $237.6 \pm 37.44$ & $259.4 \pm 34.55$ & 0.129 & $238.1 \pm 36.22$ & $246.5 \pm 49.10$ & 0.618 \\
\hline $\mathrm{PaCO}_{2}$ & $37.54 \pm 4.057$ & $37.41 \pm 5.862$ & 0.948 & $43.08 \pm 4.057$ & $39.37 \pm 4.417$ & $0.032^{*}$ \\
\hline $\mathrm{PvO}_{2}$ & $54.31 \pm 10.68$ & $54.33 \pm 0.688$ & 0.994 & $56.23 \pm 8.563$ & $53.83 \pm 6.124$ & 0.414 \\
\hline $\mathrm{PvCO}_{2}$ & $44.82 \pm 3.501$ & $44.01 \pm 3.994$ & 0.589 & $50.21 \pm 5.047$ & $46.12 \pm 3.779$ & $0.028^{*}$ \\
\hline
\end{tabular}

${ }^{*}=$ statistical significance of difference between RARC group and control group $(P<0.05)$ 
Table 4 Neuropsychological assessment

\begin{tabular}{|c|c|c|c|}
\hline & RARC group $(n=24)$ & Control group $(n=23)$ & $P$-value \\
\hline \multicolumn{4}{|l|}{ MMSE } \\
\hline Postoperative & $28.76 \pm 1.128$ & $28.77 \pm 1.110$ & 0.969 \\
\hline 1 week after operation & $28.00 \pm 1.383$ & $28.57 \pm 1.076$ & 0.133 \\
\hline 3 months after operation & $28.44 \pm 0.768$ & $28.55 \pm 1.050$ & 0.687 \\
\hline \multicolumn{4}{|l|}{ Digit Span Test } \\
\hline Postoperative & $8.500 \pm 1.022$ & $8.000 \pm 1.214$ & 0.145 \\
\hline 1 week after operation & $7.875 \pm 1.296$ & $7.238 \pm 1.136$ & 0.088 \\
\hline 3 months after operation & $8.000 \pm 1.113$ & $7.722 \pm 0.958$ & 0.409 \\
\hline \multicolumn{4}{|l|}{ Symbol Digit Modalities Test } \\
\hline Postoperative & $32.05 \pm 7.599$ & $30.25 \pm 10.21$ & 0.525 \\
\hline 1 week after operation & $27.70 \pm 8.525$ & $29.95 \pm 12.23$ & 0.483 \\
\hline \multicolumn{4}{|l|}{ Trail Making Test (sec) } \\
\hline Postoperative & $129.0 \pm 41.83$ & $109.3 \pm 26.97$ & 0.100 \\
\hline 1 week after operation & $153.5 \pm 64.30$ & $116.1 \pm 60.39$ & $0.045^{*}$ \\
\hline \multicolumn{4}{|l|}{ Brief Visuospatial Memory Test } \\
\hline Postoperative & $10.42 \pm 2.099$ & $11.45 \pm 1.697$ & 0.074 \\
\hline 1 week after operation & $10.69 \pm 2.600$ & $10.26 \pm 1.982$ & 0.566 \\
\hline \multicolumn{4}{|l|}{ Stroop Color and Word Test } \\
\hline Postoperative & $32.60 \pm 12.29$ & $33.00 \pm 9.401$ & 0.911 \\
\hline 1 week after operation & $29.44 \pm 9.071$ & $30.75 \pm 11.07$ & 0.766 \\
\hline Incidence of POCD & $11 / 24$ & $6 / 23$ & 0.135 \\
\hline
\end{tabular}

MMSE mini-mental state examination, $P O C D$ postoperative cognitive dysfunction. ${ }^{*}=$ statistical significance of difference between RARC group and control group $(P<0.05)$

position and $\mathrm{CO}_{2}$ insufflation, $\mathrm{rSO}_{2}$ slightly increased. And as the time prolonged, the $\mathrm{rSO}_{2}$ value further increased. This was probably made by a combination of increased or unchanged CPP and an increase in $\mathrm{PEtCO}_{2}$, together resulting in vasodilatation and increase of cerebral blood flow as well as a decrease in oxygen extraction ratio. Among patients who participated in our study, $\mathrm{rSO}_{2}$ values were all below $75 \%$, reflecting that Trendelenburg positioning and $\mathrm{CO}_{2}$ pneumoperitoneum didn't cause excessive perfusion. The effect of positioning and $\mathrm{CO}_{2}$ insufflation was not strong enough to break the coordination of cerebral oxygen supply and demand.

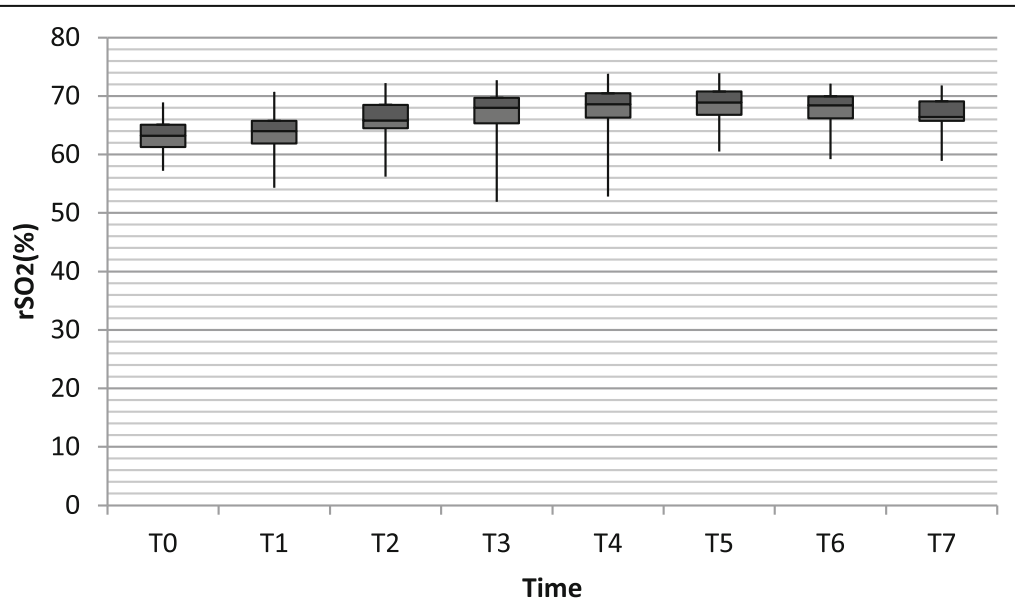

Fig. 1 The cerebral oxygen saturation in RARC group at different time points. $(T 0=$ Baseline; $T 1=$ anesthesia induction; $T 2=$ Trendelenburg position and pneumoperitoneum; $\mathrm{T} 3=1 \mathrm{~h}$ after Trendelenburg position and pneumoperitoneum; $\mathrm{T} 4=2 \mathrm{~h}$ after Trendelenburg position and pneumoperitoneum; T5 = $3 \mathrm{~h}$ after Trendelenburg position and pneumoperitoneum; $\mathrm{T} 6=$ repositioning; $\mathrm{T} 7$ = end of procedure) 


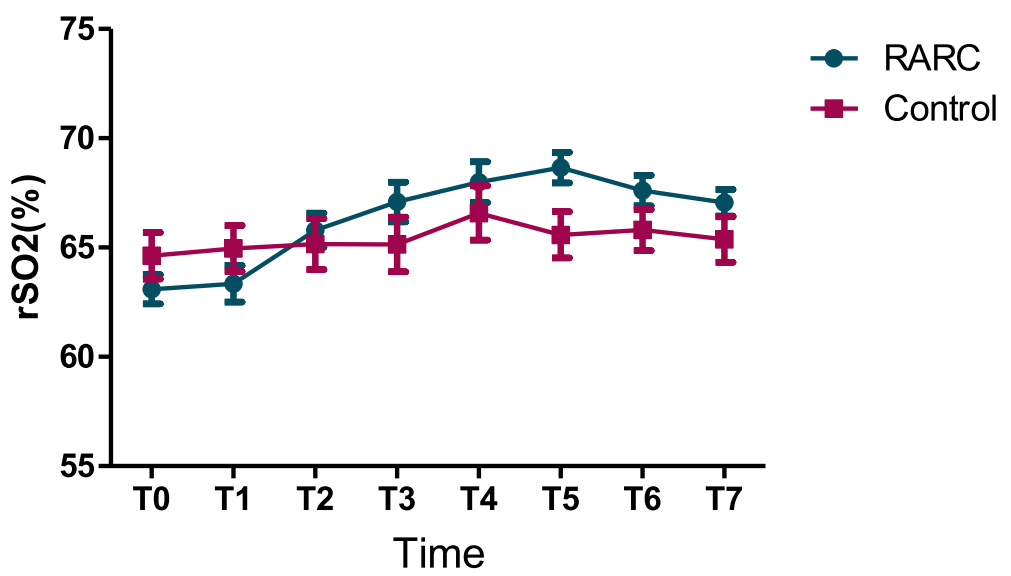

Fig. 2 The cerebral oxygen saturation in RARC group and the control group. rSO2 values increased as duration of Trendelenburg position and pneumoperitoneum prolonged in the RARC group

\section{s100 $\beta$ and CRP}

s100 $\beta$ and CRP have been shown to be increased in patients with cognitive dysfunction [21, 22] after cardiac surgery. Even so, S100 $\beta$ and CRP are not peculiar to brain tissue, which affect their diagnostic sensitivity [23, 24]. Studies about the relationship between plasma S100 $\beta$ or CRP and POCD after non-cardiac surgery indicated inconclusive results [25]. Our findings demonstrate that $\mathrm{s} 100 \beta$ and CRP were elevated $48 \mathrm{~h}$ after RARC and open abdominal surgery. In this study, it was revealed that there is no significant difference in $s 100 \beta$ and CRP between RARC and control group. These results indicated that extreme Trendelenburg positioning and $\mathrm{CO}_{2}$ pneumoperitoneum might not lead to prominently severer inflammatory response and brain injury than those open abdominal surgery in supine positioning. That might also be related to small specimens and false-positive rate. We also found that there is not a strong relationship between S100ßand cognitive dysfunction. Elevated CRP contributed to the occurrence of POCD in our study since postoperative CRP values increased significantly in the POCD group in Table 6.

\section{Limitation}

There are several limitations in the present pilot study. The crucial constraints of this study include small

Table $5 \mathrm{CRP} / \mathrm{s} 100 \beta$ of the sample (mean \pm SD)

\begin{tabular}{llll}
\hline & RARC group $(n=24)$ & Control group $(n=23)$ & P-value \\
\hline CRP & & & \\
Preoperative & $2.083 \pm 3.221$ & $2.448 \pm 2.987$ & 0.689 \\
Postoperative & $54.09 \pm 38.80$ & $61.06 \pm 29.33$ & 0.513 \\
s100 & & & \\
Preoperative & $110.2 \pm 45.79$ & $99.80 \pm 57.10$ & 0.499 \\
Postoperative & $295.4 \pm 172.9$ & $258.9 \pm 179.1$ & 0.486 \\
\hline
\end{tabular}

sample size and nonparallel control. The study seems to suggest a higher incidence rate of POCD in RARC group compared to control group, but without significant difference, which might be attributable to small sample size. Moreover, small sample size may weaken the importance of the inflammation marker CRP in prediction of POCD. Although CRP in POCD group was higher 48 $h$ after surgery than non-POCD group, its identity of reliable predictors of POCD still requires further research because we are not sure about the number of patients for statistical power and repeatability. In further study with enlarged sample size, the statistical analysis should be upgraded to a regression modeling to see whether any of the variables are predictive of POCD.

Considering small sample size and single-center study, the $P$ value was set at 0.05 . But the $P$ value of education status was less than 0.1 , showing a certain difference, which was probably a confounding factor in our study.

Table 6 Risk factors of POCD

\begin{tabular}{llll}
\hline & POCD $(n=17)$ & non-POCD $(n=30)$ & P-value \\
\hline CRP & & & \\
Preoperative & $2.243 \pm 2.691$ & $2.271 \pm 3.306$ & 0.977 \\
Postoperative & $72.59 \pm 42.09$ & $48.50 \pm 26.53$ & $0.025^{*}$ \\
s100 & & & \\
$\quad$ Preoperative & $115.3 \pm 73.29$ & $99.48 \pm 35.17$ & 0.3248 \\
$\quad$ Postoperative & $327.0 \pm 225.5$ & $250.6 \pm 138.3$ & 0.161 \\
Age & $69.20 \pm 7.033$ & $65.34 \pm 5.228$ & $0.041^{*}$ \\
Education status & $2.412 \pm 0.939$ & $2.389 \pm 1.086$ & 0.938 \\
Blood loss, ml & $176.5 \pm 163.8$ & $132.6 \pm 93.20$ & 0.241 \\
Input fluid, ml & $2044 \pm 505.9$ & $2173 \pm 582.9$ & 0.449 \\
\hline
\end{tabular}

Education status: 1 = elementary school; 2 = middle school; 3 = high school; $4=$ college/university. ${ }^{*}=$ statistical significance of difference between POCD group and non-POCD group $(P<0.05)$ 
Besides, the follow-up visit of the incidence of POCD was a relatively short period of time. Lack of long-term follow-up visit may weaken the evidence of the information.

Last but not least, the Trendelenburg position might change the proportion between intracranial and extracranial blood detection inevitably. So the signal was probably inaccurate because of blood from extracranial arteries.

\section{Conclusion}

Based on the existing sample size, no statistical significance was found to support the hypothesis that RARC increased the incidence of POCD. Extreme Trendelenburg positioning and $\mathrm{CO}_{2}$ pneumoperitoneum in RARC increased the cerebral oxygen saturation, whereas didn't cause excessive perfusion. The inflammation marker CRP and age might be independent risk factors of POCD. More samples and further studies should be put forward to investigate the mechanism and other risk factors.

\section{Abbreviations}

ABG: Arterial blood gas; ASA: American Standards Association; BMI: Body mass index; BVMT-R: Brief Visuospatial Memory Test-Revised; CRP: C-reactive protein; CVP: Central venous pressure; DST: Digit Span Test; et $\mathrm{CO}_{2}$ : End-tidal $\mathrm{CO}_{2} ; \mathrm{Hb}$ : Hemoglobin; HR: Heart rate; IAP: Intra-abdominal pressure; ICP: Intracranial pressure; MAP: Mean arterial pressure; MMSE: Mini-mental state examination; MODS: Multiple organ dysfunction syndrome; NIRS: Nearinfrared spectroscopy; POCD: Postoperative cognitive dysfunction; RARC: Robot-assisted radical cystectomy; $\mathrm{rSO}_{2}$ : Regional cerebral oxygen saturation; SCWT: Stroop Color and Word Test; TMT: Trail Making Test

\section{Acknowledgments}

Thanks are due to Xiaochun Zhao for assistance with the experiments and to Weifeng Yu for valuable discussion.

\section{Authors' contributions}

LY data mining, analysis, paper writing and part of clinical studies. LY\&HD part of clinical studies. YLQ experimental design and. SDS,CJ \& LY ideal conception, data analysis and paper writing. All authors read and approved the final version of the manuscript.

\section{Funding}

This work is supported by the Cultivated Foundation of Renji Hospital, School of Medicine, Shanghai Jiaotong University (PYII-17-009) for the publication fee. The funding body had no part in the design of the study and collection, analysis, and interpretation of data and in writing the manuscript.

\section{Availability of data and materials}

The datasets generated and analyzed during the current study are available from the corresponding author on reasonable request.

\section{Ethics approval and consent to participate}

Ethical approval was given by the institutional ethics committee (IRB of Renji Hospital, School of Medicine Shanghai Jiaotong University) and registered at Clinicaltrials.gov with registration number NCT03372135.

Written informed consent of participation is obtained from all participants.

\section{Consent for publication}

Not applicable.

\section{Competing interests}

The authors declare that they have no competing interests.
Received: 18 January 2019 Accepted: 24 October 2019

Published online: 06 November 2019

\section{References}

1. Jemal A, Bray F, Center MM, Ferlay J, Ward E, Forman D. Global cancer statistics. CA Cancer J Clin. 2011;61:69-90.

2. Kader AK, Richards KA, Krane LS, Pettus JA, Smith JJ, Hemal AK. Robotassisted laparoscopic vs open radical cystectomy: comparison of complications and perioperative oncological outcomes in 200 patients. BJU Int. 2013;112:E290-4.

3. Lawrentschuk N, Colombo R, Hakenberg OW, Lerner SP, Mansson W, Sagalowsky A, et al. Prevention and management of complications following radical cystectomy for bladder cancer. Eur Urol. 2010;57:983-1001.

4. Nix J, Smith A, Kurpad R, Nielsen ME, Wallen EM, Pruthi RS. Prospective randomized controlled trial of robotic versus open radical cystectomy for bladder cancer: perioperative and pathologic results. Eur Urol. 2010;57:196-201.

5. Wang GJ, Barocas DA, Raman JD, Scherr DS. Robotic vs open radical cystectomy: prospective comparison of perioperative outcomes and pathological measures of early oncological efficacy. BJU Int. 2008;101:89-93.

6. Gainsburg DM. Anesthetic concerns for robotic-assisted laparoscopic radical prostatectomy. Minerva Anestesiol. 2012;78:596-604.

7. Klopfenstein CE, Schiffer E, Pastor CM, Beaussier M, Francis K, Soravia C, et al Laparoscopic colon surgery: unreliability of end-tidal $\mathrm{CO} 2$ monitoring. Acta Anaesthesiol Scand. 2008;52:700-7.

8. Bloomfield GL, Ridings PC, Blocher CR, Marmarou A, Sugerman HJ. Effects of increased intra-abdominal pressure upon intracranial and cerebral perfusion pressure before and after volume expansion. J Trauma. 1996;40:936-41 discussion 41-3.

9. Josephs LG, Este-McDonald JR, Birkett DH, Hirsch EF. Diagnostic laparoscopy increases intracranial pressure. J Trauma. 1994;36:815-8 discussion 8-9.

10. Ding LL, Zhang H, Mi WD, Liu J, Jin CH, Yuan WX, et al. Anesthesia management of laparoscopic radical cystectomy and orthotopic bladder surgery with a robotic-assisted surgical system. Beijing Da Xue Xue Bao. 2013:45:819-22.

11. Kalmar AF, Foubert L, Hendrickx JF, Mottrie A, Absalom A, Mortier EP, et al. Influence of steep Trendelenburg position and CO(2) pneumoperitoneum on cardiovascular, cerebrovascular, and respiratory homeostasis during robotic prostatectomy. Br J Anaesth. 2010;104:433-9.

12. Park EY, Koo BN, Min KT, Nam SH. The effect of pneumoperitoneum in the steep Trendelenburg position on cerebral oxygenation. Acta Anaesthesiol Scand. 2009;53:895-9.

13. Ding LL, Yuan WX, Mi WD, Zhang H. Anesthesia management of artificial intelligence-assisted surgery. Int J Ane Res. 2013;8:733-6.

14. Casati A, Spreafico E, Putzu M, Fanelli G. New technology for noninvasive brain monitoring: continuous cerebral oximetry. Minerva Anestesiol. 2006;72:605-25.

15. Ballard C, Jones E, Gauge N, Aarsland D, Nilsen OB, Saxby BK, et al. Optimised anaesthesia to reduce post operative cognitive decline (POCD) in older patients undergoing elective surgery, a randomised controlled trial. PLoS One. 2012;7:e37410.

16. Fudickar A, Peters S, Stapelfeldt C, Serocki G, Leiendecker J, Meybohm P, et al. Postoperative cognitive deficit after cardiopulmonary bypass with preserved cerebral oxygenation: a prospective observational pilot study. BMC Anesthesiol. 2011;11:7.

17. Moller JT, Cluitmans P, Rasmussen LS, Houx P, Rasmussen H, Canet J, et al. Long-term postoperative cognitive dysfunction in the elderly ISPOCD1 study. ISPOCD investigators. International Study of Post-Operative Cognitive Dysfunction. Lancet. 1998;351:857-61.

18. Needham MJ, Webb CE, Bryden DC. Postoperative cognitive dysfunction and dementia: what we need to know and do. Br J Anaesth. 2017;119: i115-i25.

19. Rudolph JL, Schreiber KA, Culley DJ, McGlinchey RE, Crosby G, Levitsky S, et al. Measurement of post-operative cognitive dysfunction after cardiac surgery: a systematic review. Acta Anaesthesiol Scand. 2010;54:663-77.

20. Mitrushina M, Boone K, D'Elia L: Handbook of normative data for neuropsychological assessment. 1 edition. New York, USA: Oxford University Press; 1999

21. Nemeth E, Vig K, Racz K, Koritsanszky KB, Ronkay Kl, Hamvas FP, et al. Influence of the postoperative inflammatory response on cognitive decline in elderly patients undergoing on-pump cardiac surgery: a controlled, prospective observational study. BMC Anesthesiol. 2017;17:113. 
22. Schmidt R, Schmidt H, Curb JD, Masaki K, White LR, Launer LJ. Early inflammation and dementia: a 25-year follow-up of the Honolulu-Asia aging study. Ann Neurol. 2002;52:168-74.

23. Anand N, Stead LG. Neuron-specific enolase as a marker for acute ischemic stroke: a systematic review. Cerebrovasc Dis. 2005;20:213-9.

24. Seco M, Edelman JJ, Wilson MK, Bannon PG, Vallely MP. Serum biomarkers of neurologic injury in cardiac operations. Ann Thorac Surg. 2012;94:1026-33.

25. Peng $L$, Xu L, Ouyang $W$. Role of peripheral inflammatory markers in postoperative cognitive dysfunction (POCD): a meta-analysis. PLoS One. 2013;8:e79624

\section{Publisher's Note}

Springer Nature remains neutral with regard to jurisdictional claims in published maps and institutional affiliations.

Ready to submit your research? Choose BMC and benefit from:

- fast, convenient online submission

- thorough peer review by experienced researchers in your field

- rapid publication on acceptance

- support for research data, including large and complex data types

- gold Open Access which fosters wider collaboration and increased citations

- maximum visibility for your research: over $100 \mathrm{M}$ website views per year

At BMC, research is always in progress.

Learn more biomedcentral.com/submissions 